\title{
13. Education Reform: Learning from past experience and overseas successes
}

\author{
Robyn M Gillies
}

There is no doubt that the first decade of the twenty-first century has been characterised by an exponential increase in demands for knowledge - technoscientific, medical, social, educational, environmental, and so on - with the clear intention of transforming how we live as individuals and as a society, and of sustaining this transformation. Globalisation has increased the mobility of people, resources, and ideas. This has had an enormous impact on education and the role it must play in fostering the development of creative and informed citizens who are able to participate fully in a dynamic and changing world (Department of Education, Employment and Workplace Relations 2011, Sahlberg 2011). As a consequence, education is no longer seen as producing skilled labour to meet the demands of an industrial market-driven economy characterised by centrally planned and imposed policies and practices to meet prescribed system performance targets. Rather it is seen as the engine through which educational change can occur. We expect that schools will produce students who can bring significant improvements to the knowledge and skills needed for national economic competitiveness and increasing ecological sustainability (Hargreaves 2012).

In an attempt to ensure that these expectations are met, various Australian governments have enunciated policies which acknowledge that high quality schooling is central to achieving this vision. The Adelaide Declaration of the National Goals of Schooling (1999), ${ }^{1}$ for example, acknowledged that 'Australia's future depends upon each citizen having the necessary knowledge, understanding, skills and values for a productive and rewarding life in an educated, just and open society'. It provided broad directions to help schools and education authorities achieve these goals for students. The Melbourne Declaration of Educational Goals for Young Australians (2008) ${ }^{2}$ built on the Adelaide Declaration by recognising that globalisation and technological change place greater demands on education and skill development. People with university or vocational education qualifications have better prospects for employment than young people who leave school before they have completed high school.

\footnotetext{
1 Adelaide Declaration of the National Goals of Schooling (1999) www.mceetya.edu.au/mceecdya/ nationalgoals/index.htm, retrieved 7 February 2013.

2 Melbourne Declaration of Educational Goals for Young Australians (2008) deewr.gov.au/melbournedeclaration-educational-goals-young-people, retrieved 17 January 2013.
} 
These declarations with their associated goals recognise that Australia's future depends on all young people having the opportunity to receive a quality education to be able to participate in an increasingly globalised and complex world. National and state governments have invested billions of dollars in the last decade to:

- ensure that all young people have the right to 12 years of education

- provide a national curriculum that will enable students to acquire the knowledge, skills, and competencies needed to participate in the social, cultural, and economic development of the nation

- fund both pre-service and in-service teacher education programs to expose teachers to the latest innovations and applications in teaching, that can be used to support student educational needs and meet society's expectations.

With this investment, issues are raised about whether our schools are equipped to prepare students to meet the needs and challenges of the twenty-first century. Are we getting value for the investments we have made? There is enormous pressure on education authorities, schools, and teachers to be accountable for the education students receive. Recent debates in the media about the variability in the academic standards set by universities for admission into pre-service teacher education programs and the quality of the training received contribute to the anxiety teachers feel and the concerns the public have about teachers' competence to deliver quality education programs that reflect community expectations.

In this chapter, I discuss the types of pressures that exist, such as those that arise from national and international assessments of student achievements, enabling performances to be compared across schools and different educational jurisdictions; teacher responses to these assessment pressures, including the focus on teaching content that is likely to be tested, and the effect this has on narrowing students' curriculum experiences; teacher responses to the new national curriculum and associated changes in pedagogical innovations and practices that are required, and the effects that these changes and expectations are having on how educators think about change, and respond to it.

\section{National and international assessment programs}

In the last decade there has been an unprecedented rise in standardised assessment in schools. For example, all students in years 3, 5, 7 and 9 participate in the National Assessment Program in Literacy and Numeracy to determine whether they are meeting key performance outcomes. Results released publicly allow 
comparisons across schools and educational jurisdictions. While the original intention was to address the academic gap emerging between students and the inequities evident in divergent outcomes between schools, one unfortunate consequence has been that these data now act as league tables with potential to affect the reputation of schools that do not perform as well as expected and, possibly, their ability to attract and retain teachers and students. This alone creates enormous pressure on teachers to ensure that students meet national minimum standards and preferably perform at or above national standards, irrespective of socio-economic circumstances and support.

How then do teachers respond to these pressures? A recent survey of 8353 teachers and principals, commissioned by the Whitlam Institute and conducted by Dulfer and colleagues (2012), found that 73 per cent of teachers taught to the test (i.e. they cover content that is likely to be tested, rather than allowing the test to uncover gaps in student learning), with 46 per cent holding weekly practice tests five months before testing with the National Assessment Program in Literacy and Numeracy. This focus on testing appeared to account for 69 per cent of teachers reporting that they spend less time on teaching subjects that were not tested. Apart from the narrowing of the curriculum that often results from this type of testing (Smeed 2010), testing itself appears to adversely affect a significant number of students. Ninety per cent of teachers in the study by Dulfer and colleagues reported that the tests stressed some students. Sixty-two per cent of teachers had students who were physically distressed as a consequence.

Other assessments in the national assessment program include the Trends in International Mathematics and Science Study, ${ }^{3}$ an international assessment of mathematics and science in years 4 and 8 . This assessment is organised around a content dimension, that is, the subject matter to be taught, and a cognitive dimension (the thinking processes expected of students as they engage in the required content). While Australia's performance levels are above the scale centre point of 500 for students in years 4 and 8, they are markedly lower than student scores in Singapore, the Republic of Korea, Finland, Chinese Taipei and Japan and, in some cases, markedly lower than those in the Russian Federation, Czech Republic and Slovak Republic.

The Program for International Student Assessment is also included in the National Assessment Program. The Program for International Student Assessment aims to evaluate education systems worldwide every three years by assessing 15-year-old student competence in reading literacy, mathematical literacy, and scientific literacy. The purpose is to determine how well students are prepared to meet the challenges of the future, assess if they can analyse, reason

3 timssandpirls.bc.edu/index.html, retrieved 7 July 2014. 
and communicate their ideas effectively, and identify if there are some ways of organising schools and school learning that are more effective than others. While Australian students performed above the Organisation for Economic Co-operation and Development average, their scores in reading, mathematics, and scientific literacy were significantly lower than such countries as China (data based on Shanghai), Finland, Hong Kong, Singapore, Japan and Korea. Moreover, Australia's position in these rankings has remained virtually static for the last decade, even though we now know more about the factors that contribute to the success these countries consistently demonstrate.

Finally, the results for the Progress in International Reading Literacy Study, an international assessment of reading comprehension at year 4 that is conducted every five years, were released recently. Australia was ranked 27th out of 49 participating countries. While Australia did perform significantly higher (527) than the centre point of 500 on the scale, it ranked significantly lower than 21 other countries including Portugal (541), Hungary (539) and the Slovak Republic (535), raising concerns that our students were not performing as well as expected in the international rankings.

In summary, the results of the various assessments included in the National Assessment Program show that most Australian students are reaching expected benchmarks, or performing better than many other countries in the international mathematics and science study, ${ }^{4}$ the program for international student assessment, and the literacy study. However, concern exists that, even though there has been heavy government investment in education, Australian students are still not able to compete with Finland or a number of our Asian neighbours - average student performances on these international assessments have not changed for over a decade. The increased accountability that principals and teachers often feel as a consequence of these programs of assessment has resulted in some schools changing the curriculum to reflect the demands and requirements of these testing regimes (Smeed 2010). This action by itself has led some to question what we teach and how we teach and the effect teachers are having on student learning.

\section{Reforming the curriculum: teacher reactions}

The Australian Curriculum is currently being developed and phased in by the Australian Curriculum, Assessment and Reporting Authority, which is responsible for developing the different subjects from the Foundation Year to Year 12. The Australian Curriculum is guided by two key documents:

4 The Trends in International Mathematics and Science Study. 
the Melbourne Declaration on Educational Goals for Young Australians and the Shape of the Australian Curriculum. It includes a range of subjects such as English, arts, health and physical education, mathematics, science, history and geography. ${ }^{5}$

While every effort has been made by the authority to liaise closely with the states about implementation of the different phases of the Australian Curriculum, it appears that many teachers are still scrambling to understand the content and the processes involved in teaching the various subjects. The authority is also responsible for collecting, managing, analysing, evaluating and reporting statistical and related information about educational outcomes, including national measures for reporting the performance of Australian schooling. It is therefore easy to understand the concerns of many teachers that priority is attached to testing and measuring student performances, often at the expense of building caring teacher-student relationships, work that teachers have traditionally seen as part of their role in school (Mausethagen 2013). It is no wonder many feel increasingly disempowered and professionally marginalised (Ball 2008, Priestley et al. 2012).

Although it is still too early to evaluate the impact that the new national curriculum is having on teachers, it is possible to look at how teachers have reacted in the past to curriculum reforms that have been imposed on schools. Day and colleagues studied the commitment of 20 teachers to change in Australia and England. They found that as governments have intervened in the governance and curriculum of schools, teachers' work became 'increasingly performance orientated and audit driven, more directly accountable to a range of stakeholders, and enlarged and intensified' (Day et al. 2005, 564-5). Clandinin and colleagues $(2009,141)$ recognised that teachers live and work in 'school landscapes' that are constantly changing. Tensions are created as teachers struggle with the shifting professional knowledge landscapes that are at variance with the narratives they live by or the knowledge and practices they have as teachers. Moreno (2007) argues that in many cases these changes and their intensification have brought about a crisis in professional identity.

Others have reported similar experiences of teachers struggling to adjust to reform agendas that impose beliefs that challenge their professional identities. Kelchtermans (2005), for example, reviewed the professional biographies of a number of experienced primary teachers in Belgium. This revealed that they often felt powerless, threatened and vulnerable when they were not in control of the processes and tasks they felt professionally responsible for as teachers.

5 www.acara.edu.au/default.asp. 


\section{Teacher strategies for managing imposed change}

Teachers are very adroit at responding both overtly and covertly to imposed change. In a large-scale survey of public school teacher perceptions of imposed curriculum reform and how they coped, McCormick et al. (2005) found that many often resorted to 'palliative' coping strategies that involved cutting back and slowing down or engaging in activities that were not work-related, rather than using strategies for confronting the problem. These findings led the authors to conclude that palliative coping strategies are less likely to be effective and more likely to lead to teachers experiencing higher levels of stress in the long term. Furthermore, important problems may not be solved, and this is likely to impede the attainment of the educational authority's curriculum reform goals. These findings led the authors to argue that curriculum reform cannot be carried out in a vacuum. Teacher perceptions of the educational system within which they work are likely to influence their interpretations of the reform and its implementation.

Troman (2008) investigated the identities and commitment to teaching of primary teachers in schools where there was a focus on how the school could maximise student test scores on high-stakes tests. Although the six schools in this study were from both high and low socio-economic areas, the author reported that they all engaged in various strategies to compensate for the highstakes testing that existed in their schools. The schools in high socio-economic areas introduced curriculum enrichment experiences for their students while the schools in low socio-economic areas adopted nurturing programs to compensate for perceived academic and social deprivation of students. These actions, Troman argued, demonstrated teachers' attempts to mediate performative school cultures through their involvement in nurturing and creative projects. The actions involved increased personal effort and commitment in attempting to defend their professional values and their own identities, while adjusting to their school's commitment to high-stakes testing.

There is no doubt that teachers are experiencing enormous stress associated with the way schools change with the different policy demands, albeit with policy associated with high-stakes testing regimes and curriculum reform or professional identities. However, despite working in such contexts, Groundwater-Smith and colleagues (2001) and Hargreaves (2005) found that significant numbers of teachers remain committed to their profession, dedicated to their students, and willing to embrace innovative and cooperative teaching practices. Moreover, many recognise and manage various competing agendas by being more strategic and political in defending their professional identities while simultaneously adjusting to their public commitments in performative 
school cultures (Troman 2005). Kelchtermans (2005) also reported that teachers hold strong beliefs about what education means, and that reform agendas which impose different normative beliefs may not only trigger intense emotions but also elicit micro-political responses of resistance or proactive attempts to influence particular situations.

\section{Change that works}

The tension teachers feel from different reform agendas and change is very real. Yet it is possible, Levin (2007) argues, to have large-scale education reform that does make a difference for students, does generate public support, and does engage teachers and other education staff in a positive way. This was achieved in Ontario by the provincial education authority when it crafted a strategy to improve elementary students' literacy and numeracy, reduce class sizes, and increase high school graduation rates. By partnering with key stakeholder groups (education authorities, school boards, and provincial organisations of teachers, principals and other partners), policies and strategies were put in place that emphasised professional capacity-building, strong leadership, judicious targeting of resources (i.e. extra funding and staff) and effective parent and community engagement initiatives. These changes occurred in a context that demonstrated respect for staff and their professional knowledge so that all public statements by the government were supportive of public education and teachers. Furthermore, induction procedures rather than tests were introduced for new teachers and professional practice-sharing was encouraged. The results obtained indicate that more students per year now achieve the provincial standard for literacy and numeracy, student skill levels have increased, high school graduation rates have risen, and attrition rates for teachers leaving the profession have decreased. Thousands of teachers are participating in professional development programs and more teachers are reporting satisfaction with their work. Levin notes that the success of these efforts has resulted in more positive public positions by different stakeholder groups, including school boards and teacher unions.

Other successful reform efforts have been conducted in Finland, Singapore, and Hong Kong where students consistently perform significantly above the international average on such assessments as the Program for International Student Assessment, and Trends in International Mathematics and Science Study. This leads many educators to ask what these countries are doing that is contributing to this success. Hargreaves and Shirley $(2009,84)$ provided some insights when they commented that Finland's mediocre performance experienced a turnaround when the government actively made the decision to design 'a creative, high-skill, high-wage knowledge economy in which people invent, 
apply, share and articulate knowledge at a level that surpasses all competitors'. The results, Sahlberg (2011) reports, are that Finland has been a consistent high performer on the Program for International Student Assessment and the Trends in International Mathematics and Science Study without adopting policies on standardised teaching and learning practices, student testing, test-based accountability, and competition (these policies have been adopted by countries such as Australia, the US, the UK, Canada, Japan and New Zealand).

While Sahlberg (2011) is careful not to criticise countries that adopt these policies, he does emphasise that Finland has been successful with alternative policies revamping their educational system, so the emphasis is on investing in teachers and principals as professionals, encouraging teachers and students to try new ideas, and promoting teaching renewal while respecting schools' pedagogical legacies. Sahlberg argues that by having confidence in their teachers and schools, creativity and innovation are fostered as teachers design and pursue high quality learning and shared goals.

Singapore is another country that is a consistent high performer on the Program for International Student Assessment and the Trends in International Mathematics and Science Study. Like Finland, the government set about creating a national vision of what needed to happen if the country was to remain competitive and exceptional in the global economy. Education is seen as key to achieving this, and the government has invested heavily in it (Hargreaves 2012). It also built professional partnerships with teacher groups and actively encouraged public collaboration as a way of building a national commitment and forging a common purpose to achieving this vision. In this sense, the education system contributes to nation building and collective identity, attracting high calibre individuals to the teaching profession. Teachers are paid on a level similar to other professionals such as engineers to attract them to teaching. All teachers receive up to 100 hours of professional training each year which is paid for by the Ministry of Education. In contrast, most Australian states provide 25-30 hours.

In Singapore, there is a system-wide emphasis on developing a teacher-led culture of professional excellence which aims to promote ongoing professional learning. This is based on the belief that learning is lifelong when the learner exercises initiative, solves problems, innovates, and contributes to the greater good. Teachers are encouraged to share and collaborate with colleagues, both within and across schools, as a way of enhancing their professional knowledge and instructional practices. Teachers also have opportunities to follow different career paths with flexibility of movement between them and continuous monitoring and mentoring to ensure they are progressing satisfactorily in their career aspirations. Furthermore, students are very much seen as partners in change and in leadership, and are encouraged to be involved through mentoring and coaching programs that provide them with opportunities to lead and initiate 
change. Their involvement is seen as critical to encouraging them to accept responsibility as young citizens and invest in the success of the educational system of which they are part.

Hong Kong, like Singapore, is another high-performer on the Program for International Student Assessment and the Trends in International Mathematics and Science Study, possibly because it has embraced many of the educational practices of Finland and Singapore. It recognises that its market economy and progress rest on the talents of its people. Education is seen as an important government priority -23 per cent of its total budget is devoted to education. Curriculum reform has been at the forefront of educational change and innovation with an emphasis on student-centred learning, the development of higher level thinking skills and people skills, and a more flexible curriculum aimed at developing the whole child. In recent years, the government has invested heavily in small class teaching and teacher professional development as ways to promote quality teaching and learning in the schools and to build professional coalitions with schools in other bureaus of education in the region. ${ }^{6}$

\section{Factors mediating success}

Given the achievements of Ontario, Finland, Singapore and Hong Kong on international student assessments, what factors do they have in common that might contribute to this success? All governments have been able to articulate a clear national or provincial vision for education that is inspiring and inclusive of all its citizens. Hargreaves $(2012,12)$ argues that it is inspiring visions rather than imposed system targets that are more likely to move a whole system forward successfully and sustainably'.

Second, all governments have invested heavily in education to ensure that schools are able to achieve the vision. Money has been spent on curriculum reform, teacher professional development and training, and resources, including both personnel and material.

Third, these communities have been encouraged to help define and shape the education agenda through school boards, councils, and parent activities. Hargreaves $(2012$, 12) maintains that 'keeping the public informed of and being engaged in the development and change within the education system reduces public anxiety and helps parents and others to align their focus and to support schools'.

6 Schleicher, A (2012) Hong Kong's success in PISA: one system, many actors, oecdeducationtoday.blogspot. com.au/2012/05/hong-kongs-success-in-and-pisa, retrieved 13 January 2013. 
Fourth, teachers are encouraged to reflect on their practices, to critique and challenge current ideas with the focus on improving how they teach. To achieve this, these governments have all invested heavily in professional development and learning initiatives to ensure teachers have the latest evidence-based research and practices.

Finally, students have been encouraged to be partners in the change process through different leadership initiatives such as tutoring less able students, mentoring students from disadvantaged backgrounds, participating in schoolbased decision-making, and suggesting changes to promote better educational outcomes for all. In short, students are seen as having the ability and capacity to contribute to how education is delivered in their schools.

Many of the factors that are evident in high-performing nations are also identified by John Hattie (2011) in his book Visible learning for teachers, where he identifies the attributes of schooling that truly affect student learning. Based on more than 800 meta-analyses of research articles, Hattie argues that the quality of teaching makes the difference. Teachers are the major source of controllable variance in the school system. Using this information, Hattie outlines eight ways of thinking that underpin teachers' actions and decisions in a school. These are:

1. seeking feedback on what they need to change, enhance or continue to do as they work with students

2. believing that they can influence student success in school

3. understanding that students learn in multiple ways

4. talking with students to help them crystallise their ideas

5. recognising that assessment of student progress provides valuable feedback to teachers

6. embracing diversity and recognising the challenge this poses

7. developing positive relationships with students and staff

8. teaching parents the language of learning.

It is not hard to see that teachers who do this would also be very confident and assured as teachers, believing they can have a positive effect on students, recognising that students construct learning in many ways, and taking responsibility to help students learn. Teaching, Moreno (2007) argues, is about being close to students and caring about their lives, and about building learning communities capable of responding to the needs of students as citizens who have a right to learn. 


\section{Educators and future change}

Hargreaves (2012) argues there has been a paradigm shift in the mindset of educational leaders on how they push educational frontiers to achieve change and a more sustainable future. Many now recognise that if change is to be achieved, it requires high quality teachers, positive and powerful professional associations, and lively learning communities; the last two being contexts in which teachers practise their professional craft. In fact, Hargreaves $(2012,13)$ maintains that 'it is teachers' sense of professionalism that ultimately drives the impetus for change'.

These comments affirm Hattie's (2011) findings about the key role of teachers in effecting and managing change. While some teachers may feel stressed from different reform agendas and respond reactively to change, many others respond proactively by intervening to moderate attitudes towards testing in performative cultures when they believe these cultures badly affect student learning. Given the shifting educational landscapes of recent years, many teachers now recognise the need to develop instructional changes and ways of working that will improve student achievement, share ideas and collaborate with colleagues, and be reflective practitioners who engage in ongoing professional learning. There is no doubt that teachers who respond positively to the challenges of change are more likely to be proactive and innovative, creating new and novel approaches to their work, including building new coalitions with colleagues, parents and the wider community to help define and shape the education agenda.

\section{References}

Ball, S (2008) The education debate. Policy Press, Bristol.

Clandinin, J, Downey, C and Huber, J (2009) Attending to changing landscapes: shaping the interwoven identities of teachers and teacher educators. Asia-Pacific Journal of Teacher Education 37: 141-54.

Day, C, Elliot, B and Kingston, A (2005) Reform, standards and teacher identity: challenges of sustaining commitment. Teaching and Teacher Education 21: 563-77.

Department of Education, Employment and Workplace Relations (2011) Review of funding for schooling: final report. Australian Government, Canberra.

Dulfer, N, Polesel, J and Rice, S (2012) The experience of education: the impacts of high stakes testing on school students and their families: an educator's perspective. Whitlam Institute, University of Western Sydney. 
Change!

Groundwater-Smith, S, Brennan, M, McFadden, M and Mitchell, J (2001) Secondary schooling in a changing world. Harcourt, Sydney.

Hargreaves, A (2005) Educational change takes ages: life, career and generational factors in teachers' emotional responses to educational change. Teaching and Teacher Education 21: 967-83.

Hargreaves, A (2012) Singapore: the fourth way in action? Educational Research Policy and Practice 11: 7-17.

Hargreaves, A and Shirley, D (2009) The fourth way: the inspiring future of educational change. Corwin, Thousand Oaks, California.

Hattie, J (2011) Visible learning for teachers: maximizing the impact of learning. Routledge, Hoboken.

Kelchtermans, G (2005) Teachers' emotions in educational reforms: self-understanding, vulnerable commitment and micropolitical literacy. Teaching and Teacher Education 21: 995-1006.

Levin, B (2007) Sustainable, large-scale education renewal. Journal of Educational Change 8: 323-36.

Mausethagen, S (2013) A research review of the impact of accountability policies on teachers' workplace relations. Educational Research Review 9: 16-33.

McCormick, J, Ayres, P and Beechley, B (2005) Teaching self-efficacy, stress and coping in a major curriculum reform. Journal of Educational Administration 44: 53-70.

Moreno, J(2007) Do the initial and continuous teachers' professional development sufficiently prepare teachers to understand and cope with the complexities of today and tomorrow's education? Journal of Educational Change 8: 169-73.

Priestley, M, Edwards, R and Priestley, A (2012) Teacher agency in curriculum making: agents for change and spaces for manoeuvre. Curriculum Inquiry 42: 191-214.

Sahlberg, S (2011) The fourth way of Finland. Journal of Educational Change 12: $173-85$.

Smeed, J (2010) Accountability through high-stakes testing and curriculum change. Leading and Managing 16: 1-15.

Troman, G (2008) Primary teacher identity, commitment and career in performative school cultures. British Educational Research Journal 34: 619-33. 
This text is taken from Change! Combining Analytic Approaches with Street Wisdom, edited by Gabriele Bammer, published 2015 by ANU Press, The Australian National University, Canberra, Australia. 